\title{
Selected nitrostyrene compounds demonstrate potent activity in chronic lymphocytic leukaemia cells, including those with poor prognostic markers
}

\author{
S.A. BRIGHT ${ }^{1}$, A.J. BYRNE ${ }^{2}$, E. VANDENBERGHE ${ }^{3}$, P.V. BROWNE ${ }^{3}$, \\ A.M. McELLIGOTT ${ }^{3}$, M.J. MEEGAN ${ }^{2}$ and D.C. WILLIAMS ${ }^{1}$ \\ ${ }^{1}$ School of Biochemistry and Immunology, ${ }^{2}$ School of Pharmacy and Pharmaceutical Sciences, \\ Trinity Biomedical Sciences Institute, Trinity College Dublin, Dublin 2; ${ }^{3}$ Discipline of Haematology, School of Medicine, \\ Trinity Translational Medicine Institute, St. James's Hospital and Trinity College, Dublin 8, Republic of Ireland
}

Received October 8, 2018; Accepted March 1, 2019

DOI: $10.3892 /$ or.2019.7068

\begin{abstract}
The nitrostyrene scaffold was previously identified as a lead target structure for the development of effective compounds targeting Burkitt's lymphoma. The present study aimed to develop these compounds further in haematological malignancies, including chronic lymphocytic leukaemia (CLL). Cellular viability, flow cytometry and lactate dehydrogenase assays, amongst others, were used to examine the effects of nitrostyrene compounds on CLL cells, including a cell line representing disease with poor prognosis (HG-3) and in ex vivo CLL patient samples $(\mathrm{n}=14)$. The results demonstrated that two representative nitrostyrene compounds potently induced apoptosis in CLL cells. The pro-apoptotic effects of the compounds were found to be reactive oxygen species and caspase-dependent, and had minimal effects on the viability of
\end{abstract}

Correspondence to: Dr S. A. Bright, School of Biochemistry and Immunology, Trinity Biomedical Sciences Institute, Trinity College Dublin, 152-160 Pearse Street, Dublin 2, Republic of Ireland E-mail: brights@tcd.ie

Abbreviations: Btk, Bruton's tyrosine kinase; CAP, cyclophosphamide/doxorubicin/prednisone; CHOP, cyclophosphamide/hydroxydaunorubicin (doxorubicin)/oncovin (vincristine)/prednisone; CLL, chronic lymphocytic leukaemia; EBV, Epstein Barr virus; EMA, European Medicines Agency; FBS, foetal bovine serum; FDA, US Food and Drug Administration; LDH, lactate dehydrogenase; M-IGVH, mutated immunoglobulin heavy chain gene; 4-MTA, 4-methylthioamphetamine; $\mathrm{Nac}, \mathrm{N}$-acetyl-cysteine; $\mathrm{PBMCs}$, peripheral blood mononuclear cells; PI3K, phosphatidylinositol 3-kinase; PI, propidium iodide; PTP, protein tyrosine phosphatase; ROS, reactive oxygen species; SAR, structure activity relationship; SEM, standard error of the mean; SERT, serotonin reuptake transporter; UM-IGVH, unmutated immunoglobulin heavy chain gene; ZAP-70, serum marker z-associated protein 70

Key words: nitrostyrene, chronic lymphocytic leukaemia, B cell, idelalisib normal donor peripheral blood mononuclear cells. Nitrostyrene compounds exhibited synergistic augmentation of apoptosis when combined with the phosphatidylinositol 3-kinase inhibitor idelalisib and demonstrated potent toxicity in ex vivo CLL cells, including those co-cultured with bone marrow stromal cells, making them more resistant to apoptosis $(n=8)$. These compounds also demonstrated activity in samples from patients with poor prognostic indicators; unmutated immunoglobulin heavy chain genes, expression of CD38 and deletions in chromosomes 17p and 11q. These results suggest that this class of pharmaceutically active compounds offer potential in the treatment of CLL.

\section{Introduction}

Chronic lymphocytic leukaemia (CLL) is the most common form of leukaemia and involves the clonal expansion of abnormal B cells in the lymph nodes and/or blood. B cells, part of the adaptive immune response, function to produce antibodies against antigens; however in CLL, B cells fail to mature and differentiate correctly, eventually crowding out healthy blood cells (1). CLL is a disease which mainly affects adults and can clinically be subdivided into two major types depending on the mutational status of the immunoglobulin heavy chain gene (IGVH): Patients with CLL cells harbouring unmutated IGVH (UM-IGVH) have an average survival of 8 years, whereas patients with CLL with mutated IGVH (M-IGVH) have an average survival of $>25$ years. In addition, acquired chromosomal abnormalities involving deletions in chromosomes $11 \mathrm{q}, 13 \mathrm{q}$ and $17 \mathrm{p}$ and trisomy 12 are common in CLL, and these abnormalities predict the time to first treatment and CLL-specific survival rate. The genes principally responsible for an adverse prognosis, associated with deletions (del) in 17p13 and del11q22, have been recognised as TP53 and $A T M$, respectively (2). Other poor prognostic markers have been identified, including the lack of expression of CD38, expression of cytoplasmic marker z-associated protein 70 and, more recently, mutations in p53, Notch-1, splicing factor 3B subunit 1 and baculoviral IAP repeat-containing protein 3 (2). 
Current treatment paradigms for CLL involve use of fludarabine phosphate, cyclophosphamide and monoclonal antibodies, including rituximab (known as the FCR regime) (3). Fludarabine phosphate, the gold standard treatment for CLL, was originally synthesised in 1969 (4), and received US Food and Drug Administration (FDA)-approval for the treatment of CLL in 1991.It is a synthetic adenine nucleoside pro-drug, which is activated to a triphosphate form, F-ara-ATP. This activated form of fludarabine phosphate interferes with DNA synthesis by inhibiting ribonucleotide reductase, DNA polymerases, DNA ligase I and DNA primase. It is indicated for the firstand second-line treatment of CLL, and leads to more complete remissions (CR; 7-40\%) than other conventional chemotherapies, including cyclophosphamide/doxorubicin/prednisone (CAP) and cyclophosphamide/hydroxydaunorubicin (doxorubicin)/oncovin (vincristine)/prednisone treatment (CHOP) regimens (5). Fludarabine phosphate is also successfully used in combination with several other chemotherapeutics.

A number of more recent agents have also received European Medicines Agency (EMA) and FDA approval for the treatment of CLL: Ibrutinib, as a frontline treatment, which targets B-cell receptor signalling through the inhibition of Bruton's tyrosine kinase (Btk) (6); obinutuzumab approved in combination with chlorambucil, which is a type-2 monoclonal anti-CD20 antibody that results in direct and antibody-dependent cell-mediated cytotoxicity of leukaemia cells (7); and idelalisib approved in combination with rituximab for relapsed CLL, which inhibits B-cell receptor signalling through the inhibition of phosphatidylinositol 3-kinase (PI3K) $\delta$ molecules (8). The most recently approved CLL drug, venetoclax, is a $\mathrm{B}$-cell lymphoma $2(\mathrm{Bcl}-2)$ inhibitor. However, there are significant issues associated with these drugs, including the development of resistance, and there is an unmet need for alternative drug therapies for these diseases.

Antidepressants are a class of compounds which mimic the effects of naturally occurring neurotransmitters. They inhibit reuptake transporters, maintaining high concentrations of neurotransmitters in the synapse, and are used to treat the symptoms of depression, anxiety and several other psychological illnesses $(9,10)$.

The finding of the serotonin reuptake transporter (SERT) in B cell malignancies (11) led to the investigation of antidepressants and their analogues as potential anti-lymphoma/leukaemic agents. Activity has been demonstrated by tricyclic antidepressants citalopram, imipramine and clomipramine in HL-60 human acute myeloid leukemia cells and normal lymphocytes (12-14); and fluoxetine $(11,15,16)$, MDMA and its analogues $(11,17)$, fenfluramine (11), clomipramine (11), and maprotiline and its analogues $(15,16,18)$ in Burkitt's lymphoma cell lines. In addition, our previous studies reported on the synthesis and SERT inhibitory activity of a number of structurally related 1,3-bis(aryl)-2-nitro-1-propene and 1,3-bis(aryl)-2-propanamine compounds and identified their antiproliferative activity against Burkitt's lymphoma $(19,20)$. However, antidepressants have been shown to exhibit toxicity against a wide range of cancer cell lines (21-24), other than those of lymphatic origin, and toxicity has been reported to be independent of SERT and other transporters (15).

The drug 4-methylthioamphetamine (4-MTA) is an illegal analogue of the antidepressant amphetamine. Nitrostyrenes [(2-nitrovinyl)benzenes)] are a family of compounds based on the scaffold structure of 4-MTA. Nitrostyrene derivatives have also been reported to induce potent anticancer effects in a range of cancer cell lines; for example, nitrostyrenes have demonstrated pronounced anticancer activity in oral (25) and colon cancer (26), osteosarcoma (27) and Erlich ascetic tumour cell lines (28). Nitrostyrene derivatives have also been shown to possess a diverse range of other biological activities, including antimicrobial (29), anti-inflammatory (30) and immunosuppressive properties (31). Various mechanisms of action have been identified for nitrostyrene analogues, including tubulin inhibition (29,32), telomerase inhibition (33), protein tyrosine phosphatase (PTP) inhibition (34) and phospholipase $\mathrm{A}_{2}$ inhibition (35).

Our previous study reported on the synthesis of a library of novel analogues and structural derivatives of 4-MTA; 1,3-bis(aryl)-2-nitro-1-propene derivatives $(n=193)$, which contain a classic nitrostyrene structure, and evaluated their potential activity as antiproliferative agents against Burkitt's lymphoma (36). This screen allowed for the development of a structure-activity relationship (SAR) and an optimised nitrostyrene structure for predicted antiproliferative activity. The aim of the present study was to evaluate representative nitrostyrene compounds (Fig. 1) in a range of cancer types, with a focus on CLL.

\section{Materials and methods}

Materials. Alamar blue was obtained from BioSource Europe S.A (Nivelles, Belgium) and foetal bovine serum (FBS) was from Invitrogen; Thermo Fisher Scientific, Inc. (Waltham, MA, USA). RPMI-1640 and DMEM were sourced from Biosciences, Ltd. (Dublin, Ireland) and Lymphoprep from Axis-Shield (Oslo, Norway). Cell culture consumables were from Greiner Bio-One, Ltd. (Stonehouse, UK), and all other reagents used were from Sigma; Merck KGaA (Darmstadt, Germany). Compounds 1, 2 and 3 were prepared as previously reported (36).

Cell culture. The DG-75, BJAB and Ramos Burkitt's lymphoma cell lines were provided by Dr Dermot Walls (School of Biotechnology, Dublin City University, Dublin, Ireland). The MUTU-I (c179) cell line was provided by Professor Martin Rowe (Division of Cancer Studies, The University of Birmingham, Birmingham, UK). The EBV-transformed CLL PGA-1, I83 (M-IGVH, good prognosis), HG-3 and CII (UM-IGVH, poor prognosis) cell lines were provided by Professor Anders Rosén (Linköping University, Linköping, Sweden) (37). Other cell lines were sourced as follows: HL-60 promyelocytic leukaemia cells (cat. no. 98070106; ECACC, Salisbury, UK), HeLa cervical cancer cells (cat. no. 93021013; ECACC), MCF-7 breast cancers (cat. no. 86012803; ECACC) and HS-5 bone marrow stromal cells [cat. no. CRL-11882; American Type Culture Collection (ATCC) Manassas, VA, USA].

The CLL and HL-60 Burkitt's lymphoma cell lines were grown in RPMI-1640 (Glutamax; Thermo Fisher Scientific, Inc.) medium supplemented with $10 \%(\mathrm{v} / \mathrm{v})$ FBS and $50 \mu \mathrm{g} / \mathrm{ml}$ penicillin/streptomycin and seeded at a density of $2 \times 10^{5}$ cells $/ \mathrm{ml}$. The MUTU-I cell line also 
<smiles>CC/C(=C\c1cc(Br)ccc1OC)[N+](=O)[O-]</smiles>

1<smiles>O=[N+]([O-])/C(=C/c1ccc(Cl)cc1)Cc1ccc(Cl)cc1</smiles>
3<smiles>COc1ccc2c(c1)OC(c1ccccc1)C([N+](=O)[O-])=C2</smiles>

2

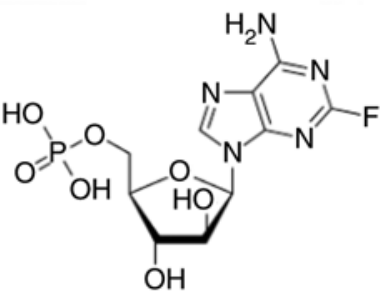

Fludarabine phosphate
Figure 1. Structure of compounds 1,2 and 3 and fludarabine phosphate.

required the additional supplements of a-thioglycerol [5 $\mathrm{mM}$ in phosphate-buffered saline (PBS) with $20 \mu \mathrm{M}$ bathocuprione disulfonic acid], sodium pyruvate $(100 \mathrm{mM})$ and HEPES (1 mM). The HS-5 bone marrow stromal, HeLa cervical cancer and MCF-7 breast cancer cell lines were grown in DMEM supplemented with $10 \%$ (v/v) FBS and $50 \mu \mathrm{g} / \mathrm{ml}$ penicillin/streptomycin and seeded at a density of $5 \times 10^{4}$ cells $/ \mathrm{ml}$. All cells were grown in a humidified environment of $37^{\circ} \mathrm{C}$ maintained at $95 \% \mathrm{O}_{2}$ and $5 \% \mathrm{CO}_{2}$ and passaged at least twice weekly depending on their levels of confluency.

Alamar blue viability assay. The cells were seeded in $200 \mu \mathrm{l}$ medium in a 96-well plate and were treated and incubated as required (up to $72 \mathrm{~h}$ ). Alamar blue $(20 \mu \mathrm{l})$ was then added to each well and incubated at $37^{\circ} \mathrm{C}$ in the dark for $4 \mathrm{~h}$. The plates were then read on a fluorescence plate reader (SpectraMax Gemini; Molecular Devices LLC, Sunnyvale, CA, USA) with excitement and emission wavelengths of 544 and $590 \mathrm{~nm}$, respectively. The experiments were performed in triplicate. A sample containing only reagent and medium (without any cells) was used as a blank control. The vehicle samples were set as $100 \%$ viability, from which any decrease in viability was calculated. To determine the $\mathrm{IC}_{50}$ values, the cells were treated with seven concentrations of nitrostyrene compounds over a range of $0.5-20 \mu \mathrm{M}(0.5,1,2.5,5,7.5,10$ and $20 \mu \mathrm{M})$ or five concentrations of fludarabine phosphate over a range of $1-50 \mu \mathrm{M}(1,5,10,20$ and $50 \mu \mathrm{M})$.

Flow cytometry. The CLL cells $\left(5 \times 10^{4}\right.$ cells $\left./ \mathrm{ml}\right)$ were treated $37^{\circ} \mathrm{C}$ with the nitrostyrene compounds for $48 \mathrm{~h}$, harvested by centrifugation at $400 \mathrm{x} \mathrm{g}$ and rinsed with $0.5 \mathrm{ml}$ of $\mathrm{Ca}^{2+}$ Annexin V-binding buffer (0.1 M HEPES, pH 7.4; $0.14 \mathrm{M} \mathrm{NaCl}$; $25 \mathrm{mM} \mathrm{CaCl}_{2}$ ). The samples were resuspended in $50 \mu \mathrm{l}$ FITC Annexin V (diluted 1:33 in $\mathrm{Ca}^{2+}$ Annexin V-binding buffer), incubated on ice for $10 \mathrm{~min}$, washed with Annexin V-binding buffer and resuspended in $500 \mu 1$ of propidium iodide (PI) solution $(0.5 \mu \mathrm{g} / \mathrm{ml})$. The samples were analysed within $1 \mathrm{~h}$ using a CyAn ADP flow cytometer (Beckman Coulter, Inc., Brea, CA, USA) counting 10,000 cells and analysed using the FlowJo software (FlowJo LLC, Ashland, OR, USA) package. Early apoptotic cells were Annexin V-positive and PI-negative, and late apoptotic cells were Annexin V-positive and PI-positive.
LDH assay. The CLL cells were seeded in $200 \mu 1$ medium in a 96-well plate, following treatment with $5 \mu \mathrm{M}$ nitrostyrene compounds for $48 \mathrm{~h}, 50 \mu \mathrm{l}$ of cell supernatants were placed in a fresh 96 well plate and $100 \mu$ l lactate dehydrogenase (LDH) assay mixture (Promega Corp., Madison, WI, USA) was added to each sample. The plate was covered with tin foil and incubated at room temperature for $30 \mathrm{~min}$. The reaction was terminated by the addition of $15 \mu \mathrm{l}$ of $1 \mathrm{~N} \mathrm{HCl}$ to each well. The absorbances of each sample were then obtained at 490 and $690 \mathrm{~nm}$. The lysis solution wells were set at $100 \%$ lysis, from which the LDH release of the treated samples was calculated.

Inhibitor experiments. The cells $\left(5 \times 10^{4}\right.$ cells $\left./ \mathrm{ml}\right)$ were pretreated at $37^{\circ} \mathrm{C}$ with either $5 \mathrm{mM} \mathrm{N}$-acetyl-cysteine (Nac) for $1 \mathrm{~h}$ or $40 \mu \mathrm{M}$ caspase inhibitor (Z-VAD; MBL International, Co., Woburn, MA, USA) for $4 \mathrm{~h}$ prior to $5 \mu \mathrm{M}$ compound treatment for $48 \mathrm{~h}$.

Co-treatment analysis. Drug interactions were determined by median dose effect analysis using CalcuSyn version 2.0 software (BioSoft, Cambridge, UK). This method is based on the drug effect equation of Chou and Talalay and can determine the degree of synergism or antagonism between two compounds by generating a combination index (CI) value. $\mathrm{CI}$ values of $<1,=1$ and $>1$ indicate synergism, an additive effect and antagonism, respectively (38).

Ex vivo CLL patient samples. Fresh peripheral blood $(10 \mathrm{ml})$ was collected with written informed consent from patients with CLL $(n=14)$ in EDTA-anticoagulant tubes. Ethical approval for all procedures performed on ex vivo CLL patient samples was obtained from the St. James's Hospital and Adelaide and Meath incorporating the National Children's Hospital Joint Ethics Committee (Dublin, Ireland). Informed consent for the use of tissues and publication of patient data was obtained from each subject in line with the Declaration of Helsinki. Patients were included if they were diagnosed with CLL, consented to the trial and were $>18$ years of age. Patients were excluded if the spontaneous background levels of apoptosis were $\geq 70 \%$. Patients were recruited between July 2013 and August 2014. The peripheral blood was diluted with an equal volume of RPMI medium and peripheral blood mononuclear cells (PBMCs) were isolated via lymphoprep ficoll gradient centrifugation at $600 \mathrm{x}$ g for $30 \mathrm{~min}$ at $4{ }^{\circ} \mathrm{C}$. The pelleted cells were resuspended in freezing medium $(10 \%$ DMSO, 90\% FBS) and frozen until required. When required, the frozen stocks were resuspended in RPMI-1640 (Glutamax) medium supplemented with $10 \%$ (v/v) FBS and $50 \mu \mathrm{g} / \mathrm{ml}$ penicillin/streptomycin, and seeded at a density of $1 \times 10^{6}$ cells $/ \mathrm{ml}$. The cells were then treated for $48 \mathrm{~h}$ with the compounds or the required vehicles and positive controls.

Statistical analysis. GraphPad Prism 5 software (GraphPad Software, Inc., La Jolla, CA, USA) was used to perform statistical analysis on all samples. For comparisons in datasets containing multiple groups, one way analysis of variance and Tukey's post hoc test was used, and $\mathrm{P}<0.05$ was considered to indicate a statistically significant difference. For comparisons in datasets containing two groups, Student's paired t-test was used. 

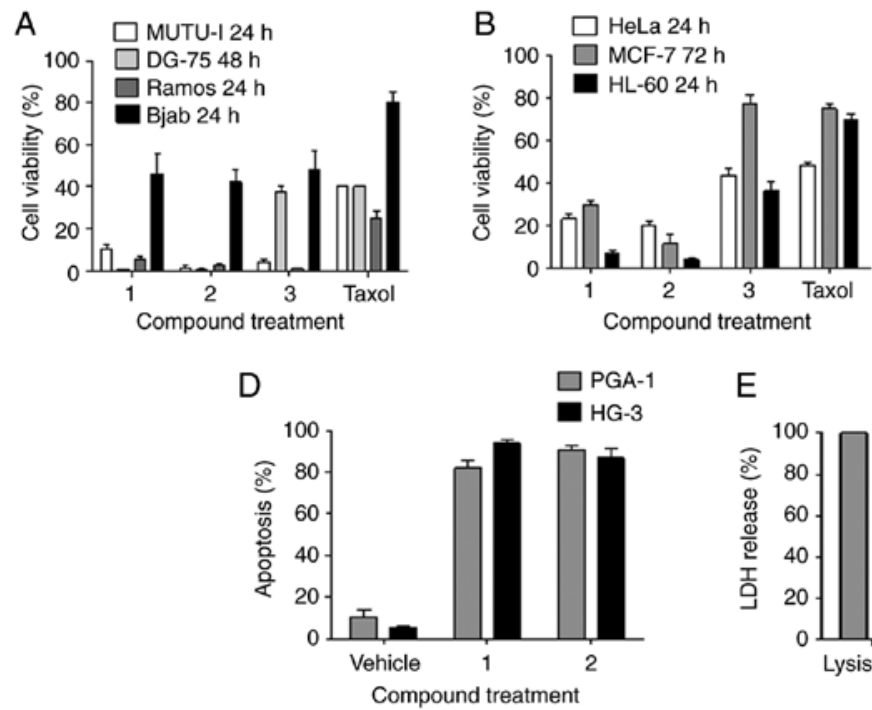

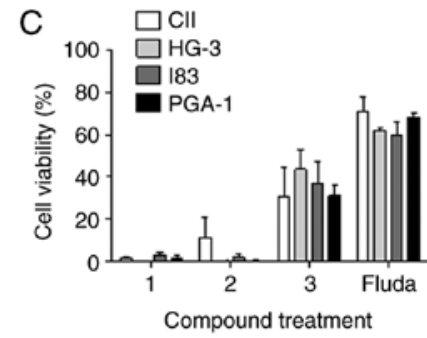

E

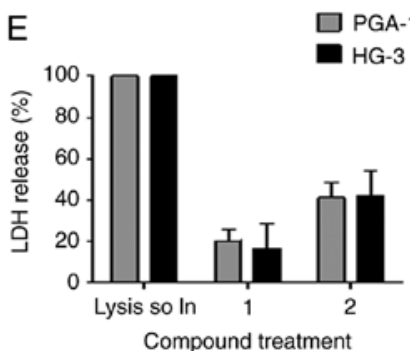

Figure 2. Nitrostyrene compounds reduce cellular viability in a range of cancer cell lines and induce apoptosis in CLL cell lines. Viability results following $10 \mu \mathrm{M}$ treatment with the indicated nitrostyrene compounds or a comparative control (Fluda or taxol) in (A) Burkitt's lymphoma, (B) solid tumour and (C) CLL cell lines. (D) Induction of early and late apoptosis in CLL cells following treatment for $48 \mathrm{~h}$ with $5 \mu \mathrm{M}$ of the indicated compounds, as determined by Annexin V and propidium iodide staining. (E) Induction of necrotic cell death in CLL cells following treatment for $48 \mathrm{~h}$ with $5 \mu \mathrm{M}$ of the indicated compounds, as determined by measuring LDH release. Values are presented as the mean \pm standard error of the mean of three independent experiments. CLL, chronic lymphocytic leukaemia; Fluda, fludarabine phosphate, LDH, lactate dehydrogenase.

\section{Results and Discussion}

Lead nitrostyrene compounds potently reduce cellular viability and induce apoptosis in a range of cancer cell lines. Representative nitrostyrene compounds, 1 (previously named 145) (36) and lead compound 2 (previously named 66) (36), together with the previous lead compound 3 (previously named 85) (20) were evaluated for their ability to reduce the viability of a range of cancerous cell lines via Alamar blue viability assays. Fludarabine phosphate was used as a comparative control for CLL cell lines, whereas taxol was used as a comparative control for all other cancer cell lines. The results demonstrated that compounds 1 and 2 potently reduced the viability of a range of Burkitt's lymphoma (Fig. 2A); HeLa, MCF-7 and HL-60 (Fig. 2B) and CLL cell lines (Fig. 2C) at a concentration of $10 \mu \mathrm{M}$. The results in Fig. $2 \mathrm{~A}$ are in agreement with previously published results (36). Of note, compounds 1 and 2 reduced the viability of all cell lines to a greater extent than either comparator compound, fludarabine phosphate or taxol.

In the CLL cell lines, the $\mathrm{IC}_{50}$ values obtained were in the low micromolar range for compounds 1 and $2(2-5 \mu \mathrm{M})$ and were $\sim 2$-3-fold lower than the $\mathrm{IC}_{50}$ values obtained for compound 3. Fludarabine phosphate, the current frontline treatment for CLL, was significantly less active than the nitrostyrene compounds, with $\mathrm{IC}_{50}$ values of between 20 and $50 \mu \mathrm{M}$ (4-15-fold higher than for 1 and 2 . The $\mathrm{IC}_{50}$ values for the nitrostyrene compounds were similar across all four cell lines, irrespective of IGVH mutational status (I83 and PGA-1: M-IGVH; HG-3 and CII: UM-IGVH) (Table I).

The PGA-1 and HG-3 cell lines (39) were selected for subsequent experiments to investigate the ability of the compounds to induce apoptosis in these two cell lines. The cells underwent a significant increase in apoptosis, as determined using Annexin V and PI staining (Fig. 2D). In agreement
Table I. $\mathrm{IC}_{50}$ values following treatment with the indicated compounds for $48 \mathrm{~h}$ in chronic lymphocytic leukaemia cell lines.

\begin{tabular}{lcccc}
\hline & \multicolumn{4}{c}{$\mathrm{IC}_{50}(\mu \mathrm{M})$} \\
\cline { 2 - 5 } Compound & CII & HG-3 & I83 & PGA-1 \\
\hline Fluda & 49.9 & 28.1 & 20.7 & 32 \\
1 & 3.46 & 2.54 & 4.74 & 2.9 \\
2 & 3.46 & 3.08 & 4.13 & 2.17 \\
3 & 8.05 & 8.69 & 8.43 & 6.74 \\
\hline
\end{tabular}

Fluda, fludarabine phosphate.

with these results, compound 1 induced only a low percentage of LDH release, indicative of necrosis, an alternative but less desirable form of cell death from a clinical point of view due to its inflammatory effects. Compound 2 induced a higher, but moderate percentage of LDH release (Fig. 2E).

Lead nitrostyrene-induced cell death is reactive oxygen species (ROS)- and caspase-dependent. Pretreatment of the cells with $\mathrm{N}$-acetyl-cysteine (Nac), a ROS inhibitor, caused a significant reduction in nitrostyrene-induced apoptosis compared with that in cells treated with the nitrostyrene compo unds alone (Fig. 3A and B). ROS are normally produced in low number as a toxic by-product following oxidative phosphorylation in the mitochondria; the results suggested that the target of nitrostyrene compounds 1 and 2 may be the mitochondria. Further experiments revealed that the inhibition of caspases, which are intracellular cysteine proteases commonly associated 
$\square$ Early apoptosis

Late apoptosis

A

A

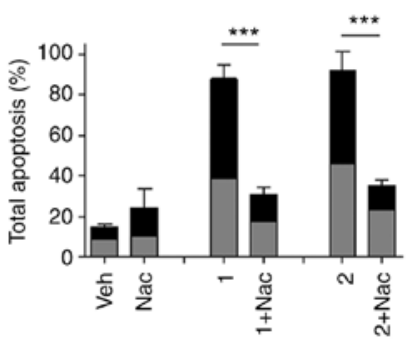

C

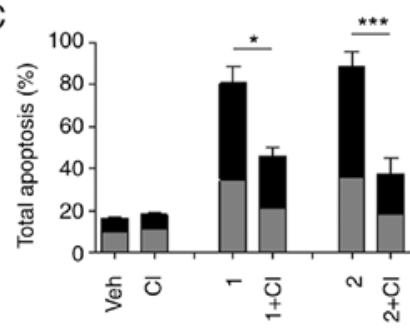

B
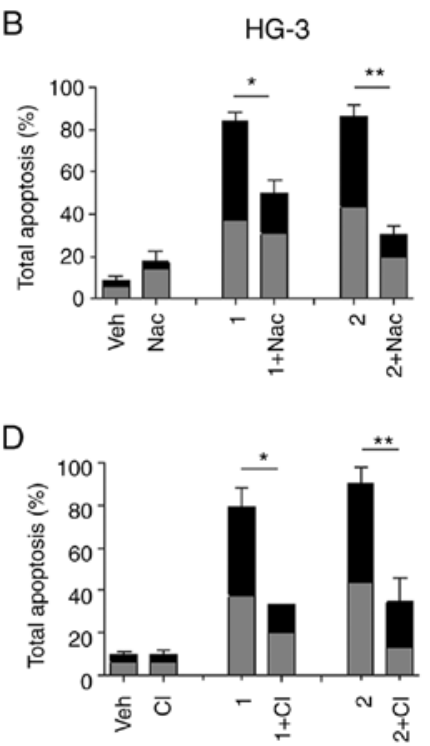

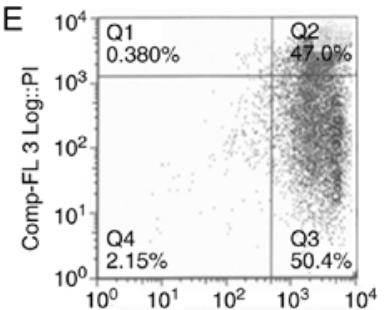

Com-FL 1 Log:FITC Annexin V

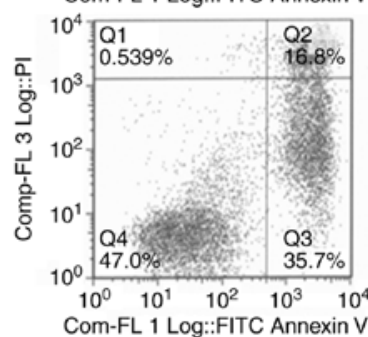

Com-FL 1 Log:FITC Annexin V

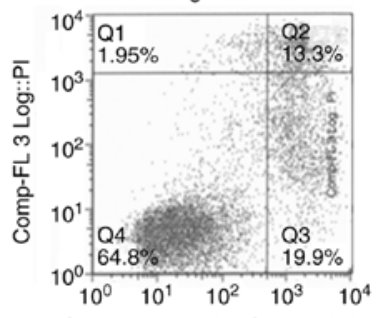

Com-FL 1 Log::FITC Annexin V

Figure 3. Nitrostyrene analogue-induced apoptosis is caspase- and ROS-dependent. CLL cells were pretreated with the ROS inhibitor (5 mM Nac) for $1 \mathrm{~h}$ or the $\mathrm{CI}(40 \mu \mathrm{M}$ Z-VAD) for $4 \mathrm{~h}$, followed by treatment for a further $48 \mathrm{~h}$ with $5 \mu \mathrm{M}$ of the indicated nitrostyrene compounds. Cells were subsequently analysed for apoptosis by Annexin V and PI flow cytometry. Early apoptotic cells were Annexin V-positive, PI-negative, late apoptotic cells were Annexin V-and PI-positive. (A) PGA-1 cells, ROS inhibition, (B) HG-3 cells, ROS inhibition, (C) PGA-1 cells, caspase inhibition and (D) HG-3 cells, caspase inhibition. Values are presented as the mean \pm standard error of the mean of three independent experiments. ${ }^{*} \mathrm{P}<0.05 ;{ }^{* *} \mathrm{P}<0.01 ;{ }^{* * *} \mathrm{P}<0.001$. (E) Representative dot plots of HG-3 cells treated with (top) $5 \mu \mathrm{M}$ compound 1 , (middle) Nac $+5 \mu \mathrm{M}$ compound 1 and (bottom) CI $+5 \mu \mathrm{M}$ compound 1 . CLL, chronic lymphocytic leukaemia; ROS, reactive oxygen species; $\mathrm{CI}$, caspase inhibitor; PI, propidium iodide; Veh, vehicle; Nac, $\mathrm{N}$-acetyl-cysteine.

$\square$ Early apoptosis

Late apoptosis

A

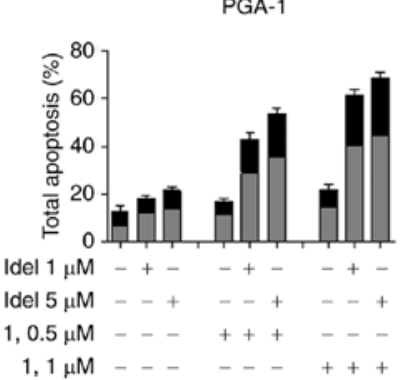

C

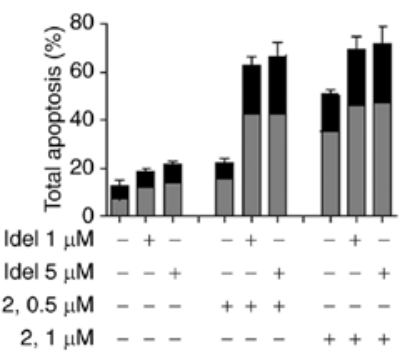

B

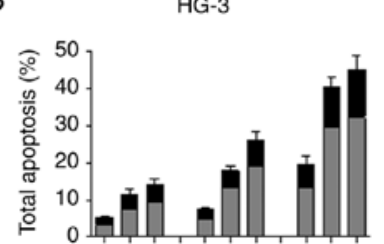

Idel $1 \mu \mathrm{M}-+-{ }_{-}+-+$

Idel $5 \mu \mathrm{M}-\mathrm{H}_{-}+\ldots+$

$1,0.5 \mu \mathrm{M}---+++---$

$1,1 \mu \mathrm{M}-\ldots+\ldots+++$

D

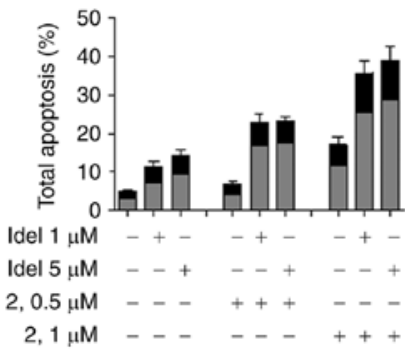

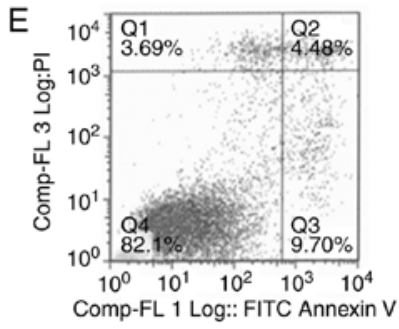
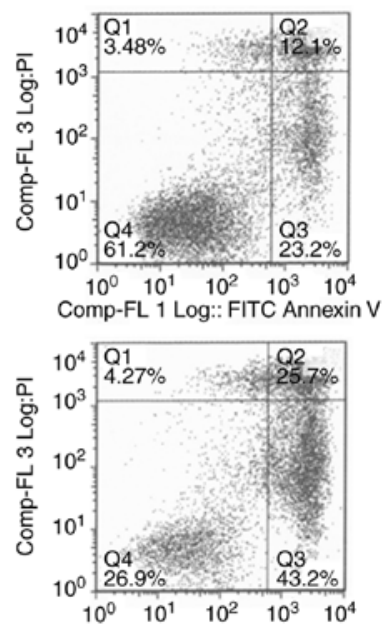

Comp-FL 1 Log:: FITC Annexin V

Figure 4. Idel synergistically enhances the apoptotic effect of lead nitrostyrene compounds in CLL cell lines. CLL cells were treated for $48 \mathrm{~h}$ with the indicated compounds and subsequently analysed for apoptosis by Annexin V and propidium iodide flow cytometry. (A) PGA-1 cells, compound 1; (B) HG-3 cells, compound 1; (C) PGA-1 cells, compound 2; and (D) HG-3 cells, compound 2. Values are presented as the mean \pm standard error of the mean of three independent experiments. (E) Representative dot plots of PGA-1 cells treated with (top) $1 \mu \mathrm{M}$ Idel, (middle) $1 \mu \mathrm{M}$ compound 1 and (bottom) $1 \mu \mathrm{M}$ Idel $+1 \mu \mathrm{M}$ compound $1+$ CI. CLL, chronic lymphocytic leukaemia; Idel, idelalisib. 
with apoptosis, significantly reduced the percentage of cells undergoing apoptosis following treatment with nitrostyrene compounds 1 and 2, suggesting a caspase-dependent form of cell death may be occurring (Fig. 3C and D). Representative dot plots are shown for illustrative purposes (Fig. 3E). These results are in agreement with those of previous studies on nitrostyrene analogues and the involvement of caspases. For example, caspase activation was observed with trans- $\beta$-nitrostyrene in LoVo adenocarcinoma cells (40), two nitrostyrene derivative compounds (NTS1 and NTS2) in Ehrlich ascitic tumour cells (28) and 2-aryl-3-nitro- $2 \mathrm{H}$-chromenes in breast cancer cells (41).

Lead nitrostyrene compounds synergistically enhance the effect of idelalisib. Few cancer treatments exist as a standalone therapy, so it is important to develop small molecule inhibitors that can potentiate the effects of other treatments. Idelalisib, a PI3K-inhibitor, has recently been FDA-approved for the treatment of relapsed CLL in combination with rituximab and EMA-approved in combination with rituximab or ofatumumab (8). Therefore, the present study aimed to determine whether idelalisib augments the apoptotic effect of the lead nitrostyrene compounds, or vice versa. The results demonstrated that treatment with $1 \mu \mathrm{M}$ of compound 1 alone caused $22.0 \pm 7.5 \%$ of cells to undergo apoptosis, however, following co-treatment with $5 \mu \mathrm{M}$ idelalisib, increased this apoptosis to a mean of $68.4 \pm 8.0 \%$ in the PGA-1 cells (Fig. 4A). Similar increases in apoptosis were also obtained in the HG-3 cells treated with compound 1 (Fig. 4B) and in the PGA-1 and HG-3 cells treated with compound 2, respectively (Fig. 4C and D). Representative dot plots are shown for illustrative purposes (Fig. 4E). The median dose analysis showed that, for all combinations assessed in both CLL cell lines, a CI value of $<1$ was obtained, indicating synergism between the compounds (Table II). These results are in agreement with a variety of other anticancer agents that have been shown to synergise with idelalisib, including the Syk inhibitor GS-9973 (42), histone deacetylase inhibitor panobinostat (LBH589) and suberoylanilide hydroxamic acid (43) and ibrutinib (44). Reports of nitrostyrenes in combination with other anticancer agents are limited; however, nitrostyrenes have previously been documented to synergise with another anticancer agent, 5-fluorouracil, in colon cancer cells in vitro (40).

Lead nitrostyrene compounds potently induce apoptosis in ex vivo CLL patient samples, including those with poor prognostic indicators. The present study investigated whether these novel nitrostyrene compounds were also capable of inducing apoptosis in cancer cells isolated from patients with CLL. For this, informed consent was obtained from a cohort of patients with CLL $(n=14)$; the details of these patients are outlined in Table III. Of these 14 patients, three were women and 11 were men, and the cohort ranged in age between 49 and 78 years.

The PBMCs were isolated from the blood samples of patients with CLL by Ficoll gradient and stored in liquid nitrogen in biobanking facilities until required. Primary CLL cells are known to die rapidly in culture and as a result underwent a high and varied background level of spontaneous
Table II. Median dose effect analysis of CLL cell lines.

\begin{tabular}{lcccc}
\hline Treatment & $\begin{array}{c}\text { Idelalisib } \\
(\mu \mathrm{M})\end{array}$ & $\begin{array}{c}\text { Nitrostyrene } \\
(\mu \mathrm{M})\end{array}$ & $\mathrm{Fa}$ & $\mathrm{CI}$ \\
\hline HG-3 & & & & \\
Idelalisib-1 & 1 & 0.5 & 0.179 & 0.774 \\
combination & 1 & 1 & 0.403 & 0.759 \\
& 5 & 0.5 & 0.259 & 0.588 \\
& 5 & 1 & 0.452 & 0.680 \\
Idelalisib-2 & 1 & 0.5 & 0.228 & 0.482 \\
combination & 1 & 1 & 0.357 & 0.639 \\
& 5 & 0.5 & 0.231 & 0.545 \\
& 5 & 1 & 0.391 & 0.589 \\
PGA-1 & & & & \\
Idelalisib-1 & 1 & 0.5 & 0.429 & 0.416 \\
combination & 1 & 1 & 0.616 & 0.475 \\
& 5 & 0.5 & 0.537 & 0.301 \\
& 5 & 1 & 0.684 & 0.380 \\
Idelalisib-2 & 1 & 0.5 & 0.627 & 0.284 \\
combination & 1 & 1 & 0.693 & 0.445 \\
& 5 & 0.5 & 0.667 & 0.246 \\
& 5 & 1 & 0.720 & 0.400
\end{tabular}

Analysis was performed using Calcusyn software. CI values of $>1,=1$ and $<1$ indicates antagonism, an additive effect and synergism, respectively. Fa, fraction of cells affected by apoptosis; CI, combination index.

apoptosis in the present study. Therefore, the results are presented as the increase in apoptosis observed following treatment with compound 1 or 2 over vehicle-treated cells. The cells were incubated with a range of concentrations of compounds 1 and 2 for $48 \mathrm{~h}$. The results demonstrated CLL cells underwent a significant dose-dependent increase in apoptosis when treated with representative lead nitrostyrene compounds. Apoptosis increased, on average by $15.4 \pm 2.6 \%$ when treated with $250 \mathrm{nM}$ compound 1 (range, -2.6-29.8\%). This increased to $44.9 \pm 5.7 \%$ apoptosis when treated with $10 \mu \mathrm{M}$ compound 1 (range, 23.2-81.9\%) (Fig. 5A). Similarly, cells underwent an average increase in apoptosis of $15.8 \pm 3.6 \%$ (range, $0.3-43.6 \%$ ) and $43.7 \pm 6.0 \%$ (range, 23.2-80.3\%) following treatment with 250 and $10 \mu \mathrm{M}$ compound 2, respectively (Fig. 5B). By contrast, patient samples treated with fludarabine phosphate underwent a lower increase in apoptosis of $24.6 \pm 4.0 \%$ (range, $4.0-49.0 \%$ ) at the highest concentration of $50 \mu \mathrm{M}$ (Fig. 5C).

The samples treated with compound 1 demonstrated similar levels of apoptosis when harbouring poor clinical markers (UM-IGVH, CD38-, del17p and del11q) compared with samples with favourable clinical markers (M-IGVH, CD38+) (Fig. 6A-C). Similar results were obtained for compound 2 (Fig. 6D-F). These chromosomal abnormalities are associated with clinically progressive disease, shorter remission durations and shorter overall survival rates following standard chemotherapy (2). 
Table III. List of patient details.

\begin{tabular}{cccclc}
\hline Patient no. & Age (years) & Sex & Binet stage & Karyotype & CD38 \\
\hline 1 & 78 & M & A & ND & Negative \\
2 & 60 & M & C & Del13q, Del 11q & Positive \\
3 & 68 & M & A & ND & ND \\
4 & 66 & M & A & Del13q, Del17p & Negative \\
5 & 72 & M & B & Del11q & Negative \\
6 & 78 & F & A & Normal & UM \\
7 & 49 & F & A & Del13q & Negative \\
8 & 78 & M & A & ND & M \\
9 & 72 & M & A & ND & NDative \\
10 & 61 & F & A & Del17p & Negative \\
11 & 59 & M & C & Normal & ND \\
12 & 57 & M & B & Del13q & Negative \\
13 & 69 & M & A & ND & UM \\
14 & 73 & M & A & Normal & Negative
\end{tabular}

ND Positive patients have $\geq 30 \%$ leukaemic cells positive for CD38. IGVH, immunoglobulin heavy chain gene; M, mutated; UM, unmutated; Del, chromosomal deletion; ND, not determined.
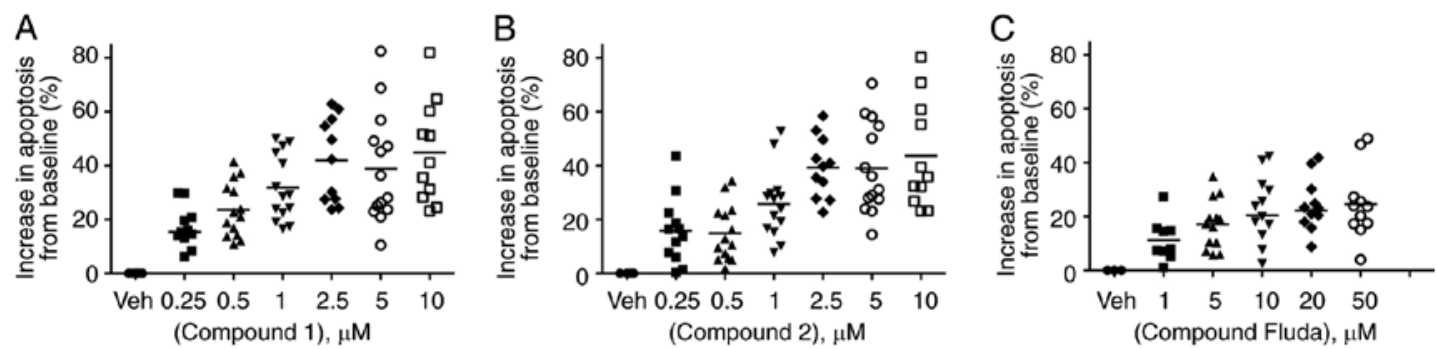

Figure 5. Nitrostyrene analogues induce more potent apoptosis in ex vivo CLL patient samples than Fluda. Peripheral blood mononuclear cells were isolated with informed consent from 14 patients with CLL, incubated with the indicated concentration of compounds 1 and 2 for $48 \mathrm{~h}$ and analysed for apoptotic cell death. Fluda was used as a comparable control. (A) Compound 1, (B) compound 2 and (C) Fluda. Graphs represent the increase in early and late apoptosis from baseline. CLL, chronic lymphocytic leukaemia; Veh, vehicle; Fluda, fludarabine phosphate.

A

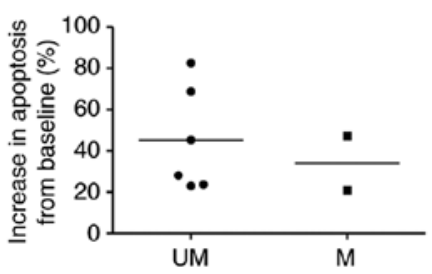

D

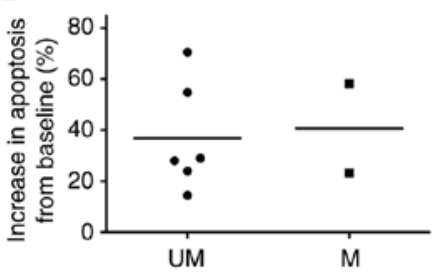

B

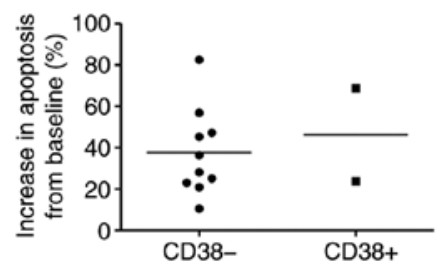

$\mathrm{E}$

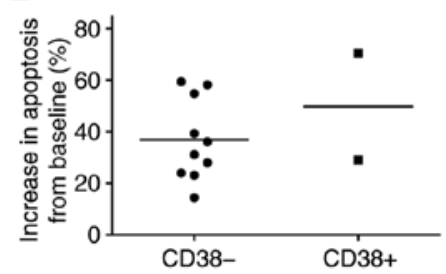

C

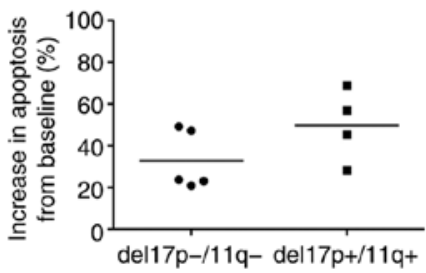

$\mathrm{F}$

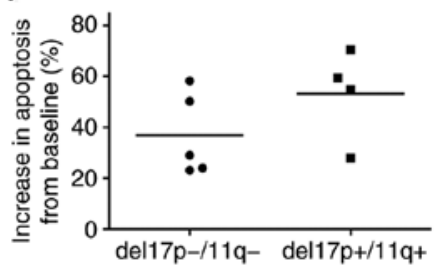

Figure 6. Nitrostyrene analogues potently induce apoptosis in poor prognosis ex vivo CLL patient samples. Peripheral blood mononuclear cells were isolated with informed consent from CLL patients and incubated with $5 \mu \mathrm{M}$ of either compounds 1 or 2 for $48 \mathrm{~h}$ and analysed for apoptotic cell death. Apoptosis results are presented for compound 1 by (A) IGVH status, (B) CD38 status and (C) karyotype, and for compound 2 by (D) IGVH status, (E) CD38 status and (F) karyotype. Poor prognostic factors include UM-IGVH, CD38, del17 ${ }^{+}$or del11 $\mathrm{q}^{+}$. Graphs represent the increase in early and late apoptosis from baseline. CLL, chronic lymphocytic leukaemia; IGVH, immunoglobulin heavy chain gene; M, mutated; UM, unmutated. 

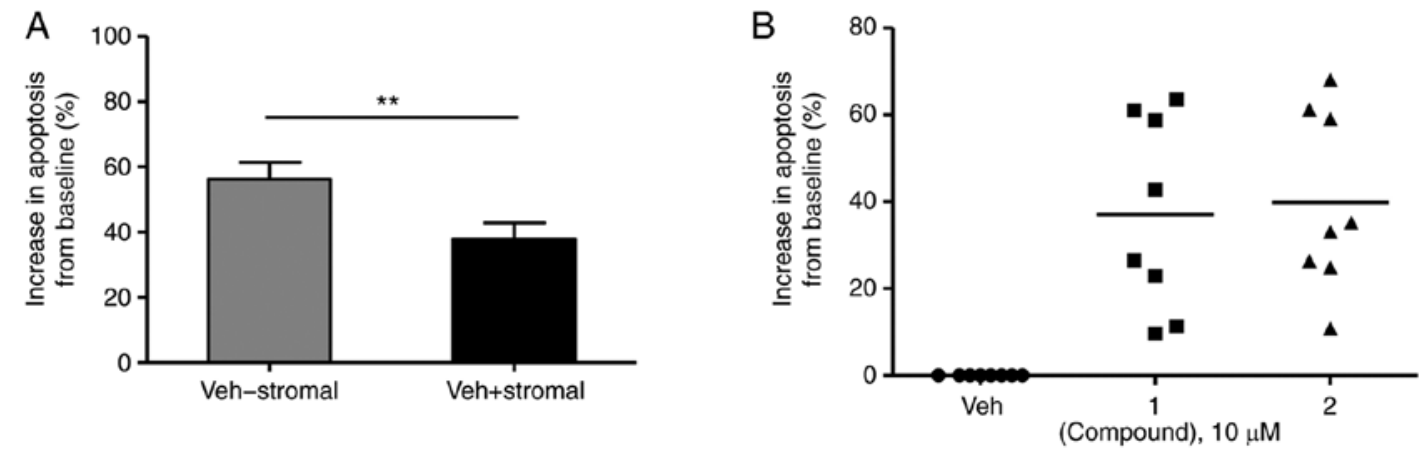

Figure 7. Nitrostyrene analogues overcome resistant ex vivo CLL cells. Peripheral blood mononuclear cells from eight patients with CLL were cultured with stromal H5S cells to mimic their microenvironment. Cells were subsequently treated with $10 \mu \mathrm{M}$ of the indicated compounds for $48 \mathrm{~h}$ and analysed for apoptotic cell death. (A) Microenvironment increases survival of ex vivo CLL cells. (B) Resistant CLL cells underwent apoptosis when treated with nitrostyrenes. Graphs represent the increase in early and late apoptosis from baseline. ${ }^{* *} \mathrm{P}<0.01$. CLL, chronic lymphocytic leukaemia; Veh, vehicle.

CLL cells in vivo are known to be resistant to apoptosis, assisted by interactions with lymph node and bone marrow microenvironments. CLL cells adhering to bone marrow stromal cells through integrins show decreased protein levels of the anti-apoptotic Bcl-2 and are influenced by stromal cell secretion of interleukin IL-4 and interferon- $\alpha / \lambda(45,46)$. In order to mimic this microenviromental-mediated resistance of cancer cells to apoptosis, primary CLL cells $(n=8)$ were co-cultured with bone marrow-derived stromal HS5 cells. As a result, primary untreated CLL cells developed a greater ability to survive in culture, with spontaneous background apoptotic levels dropping significantly by almost $20 \%$ from $56.2 \pm 5.1$ to $37.9 \pm 5.0 \%$ (Fig. $7 \mathrm{~A}$ ). The co-cultured ex vivo primary CLL cells also underwent a significant increase in apoptosis following co-treatment with $10 \mu \mathrm{M}$ compound 1 and 2 of $37.0 \pm 7.9$ (range, $9.6-63.5 \%$ ) and $39.9 \pm 7.2 \%$ (range, 10.8-68.1\%), respectively (Fig. 7B). This suggests the ability of nitrostyrene compounds to overcome the drug resistance afforded to primary CLL cells by their in vivo microenvironment.

Although nitrostyrene derivatives have been confirmed to be potent at inducing apoptosis in a wide variety of cell types, reports on clinical development are limited; however, Bartels et al demonstrated the successful in vivo application of two nitrostyrene derivatives in a BALB/c myelopoiesis model mouse model (47). The results outlined above suggest the clinical potential for the development of novel nitrostyrene compounds as a treatment for CLL, and the study by Bartels et al suggests that nitrostyrene compounds are well tolerated in vivo.

Drugs used to treat CLL include fludarabine phosphate, rituximab, the PI3K inhibitor idelalisib and the Btk inhibitor ibrutinib (1). However, there are significant issues associated with these drugs, including the development of resistance, and an unmet requirement is emerging for alternative drug therapies for this disease. In the present study, it was demonstrated that lead nitrostyrene compounds offer potential for the treatment of CLL (compounds 1, 2 and 3). Although the original target of nitrostyrene compounds was considered to be SERT, which is overexpressed in a number of cancer types, it is now known that SERT is not connected with the compound mechanism of action. As a result, the molecular target of these compounds remains to be elucidated. However, numerous studies on structurally similar compounds have pointed to a diverse range of potential targets, including tubulin $(29,32)$, telomerases (33), protein tyrosine phosphatases (34) and phospholipase $A_{2}$ (35). Follow-up investigations into these target/s are ongoing.

In the present study, two lead nitrostyrene compounds with aryl substitutions, compounds 1 and 2, potently reduced cell viability in a broad range of cancer cell lines, including CLL cells, associated with a poor prognosis. These lead compounds demonstrated significantly higher potent antiproliferative activity than the conventional drug treatment fludarabine phosphate and demonstrated $\mathrm{IC}_{50}$ values of $<10 \mu \mathrm{M}$ for all CLL cells. The apoptotic cell death was caspase and ROS-dependent and was significantly and synergistically enhanced by idelalisib. The compounds also successfully induced apoptosis in primary cells from patients with CLL, including those with poor prognostic markers. The compounds also overcame stromal cell-induced chemoresistance in CLL cells. These results demonstrate the potential of nitrostyrene analogues for the treatment of CLL.

\section{Acknowledgements}

Not applicable.

\section{Funding}

Funding was provided by Trinity College Dublin.

\section{Availability of data and materials}

The corresponding author can be contacted for more information.

\section{Authors' contributions}

SAB performed the majority of the experiments and wrote the manuscript; AJB performed some experiments and synthesized the compounds; EV provided access to the patient samples; EV, PVB, AMM, MJM and DCW contributed to the design of the study and supervised the project. All authors read and approved the manuscript and agree to be accountable for all aspects of the research in ensuring that the accuracy or integrity of any part of the work are appropriately investigated and resolved. 


\section{Ethics approval and consent to participate}

Ethical approval for all procedures performed on ex vivo CLL patient samples was obtained from the St. James's Hospital and Adelaide and Meath incorporating the National Children's Hospital Joint Ethics Committee (Dublin, Ireland). Informed consent for the use of tissues was obtained from each subject in line with the Declaration of Helsinki.

\section{Patient consent for publication}

Informed consent for publication of patient data was obtained from each subject in line with the Declaration of Helsinki.

\section{Competing interests}

The authors declare that they have no competing interests.

\section{References}

1. Nabhan C and Rosen ST: Chronic lymphocytic leukemia: A clinical review. JAMA 312: 2265-2276, 2014

2. Puiggros A, Blanco G and Espinet B: Genetic abnormalities in chronic lymphocytic leukemia: Where we are and where we go. Biomed Res Int 2014: 435983, 2014.

3. Skarbnik AP and Faderl S: The role of combined fludarabine, cyclophosphamide and rituximab chemoimmunotherapy in chronic lymphocytic leukemia: Current evidence and controversies. Ther Adv Hematol 8: 99-105, 2017.

4. Montgomery JA and Hewson K: Nucleosides of 2-fluoroadenine. J Med Chem 12: 498-504, 1969.

5. Hallek M: Chronic lymphocytic leukemia: 2017 update on diagnosis, risk stratification, and treatment. Am J Hematol 92: 946-965, 2017.

6. Aalipour A and Advani RH: Bruton's tyrosine kinase inhibitors and their clinical potential in the treatment of B-cell malignancies: focus on ibrutinib. Ther Adv Hematol 5: 121-133, 2014.

7. Shah A: New developments in the treatment of chronic lymphocytic leukemia: Role of obinutuzumab. Ther Clin Risk Manag 11: $1113-1122,2015$

8. Shah A and Mangaonkar A: Idelalisib: A novel PI3Kס inhibitor for chronic lymphocytic leukemia. Ann Pharmacother 49: 1162-1170, 2015.

9. Duman RS: Neurobiology of stress, depression, and rapid acting antidepressants: Remodeling synaptic connections. Depress Anxiety 31: 291-296, 2014

10. Gold PW, Machado-Vieira R and Pavlatou MG: Clinical and biochemical manifestations of depression: Relation to the neurobiology of stress. Neural Plast 2015: 581976, 2015.

11. Meredith EJ, Holder MJ, Chamba A, Challa A, Drake-Lee A, Bunce CM, Drayson MT, Pilkington G, Blakely RD, Dyer MJ, et al: The serotonin transporter (SLC6A4) is present in B-cell clones of diverse malignant origin: probing a potential antitumor target for psychotropics. FASEB J 19: 1187-1189, 2005.

12. Xia Z, Bergstrand A, DePierre JW and Nassberger L: The antidepressants imipramine, clomipramine, and citalopram induce apoptosis in human acute myeloid leukemia HL-60 cells via caspase-3 activation. J Biochem Mol Toxicol 13: 338-347, 1999.

13. Xia Z, DePierre JW and Nassberger L: Modulation of apoptosis induced by tricyclic antidepressants in human peripheral lymphocytes. J Biochem Mol Toxicol 12: 115-123, 1998.

14. Xia Z, Karlsson H, De Pierre JW and Nassberger L: Tricicylic antidepressants induce apoptosis in human T-lymphocytes. Int J Immunopharmacol 19: 645-654, 1997.

15. Cloonan SM, Drozgowska A, Fayne D and Williams DC: The antidepressants maprotiline and fluoxetine have potent selective antiproliferative effects against Burkitt lymphoma independently of the norepinephrine and serotonin transporters. Leuk Lymphoma 51: 523-539, 2010.

16. Cloonan SM and Williams DC: The antidepressants maprotiline and fluoxetine induce Type II autophagic cell death in drug-resistant Burkitt's lymphoma. Int J Cancer 128: 1712-1723, 2011.
17. Gandy MN, McIldowie M, Lewis K, Wasik AM, Salomonczyk D, Wagg K, Millar ZA, Tindiglia D, Huot P, Johnston T, et al: Redesigning the designer drug ecstasy: Non-psychoactive MDMA analogues exhibiting Burkitt's lymphoma cytotoxicity. Med Chem Commun 1: 287-293, 2010.

18. McNamara YM, Bright SA, Byrne AJ, Cloonan SM, McCabe T, Williams DC and Meegan MJ: Synthesis and antiproliferative action of a novel series of maprotiline analogues. Eur J Med Chem 71: 333-353, 2014.

19. Cloonan SM, Keating JJ, Butler SG, Knox AJ, Jørgensen AM, Peters GH, Rai D, Corrigan D, Lloyd DG, Williams DC, et al: Synthesis and serotonin transporter activity of sulphur-substituted alpha-alkyl phenethylamines as a new class of anticancer agents. Eur J Med Chem 44: 4862-4888, 2009.

20. McNamara YM, Cloonan SM, Knox AJ, Keating JJ, Butler SG, Peters GH, Meegan MJ and Williams DC: Synthesis and serotonin transporter activity of 1,3-bis(aryl)-2-nitro-1-propenes as a new class of anticancer agents. Bioorg Med Chem 19: 1328-1348, 2011.

21. Kinjo T, Kowalczyk P, Kowalczyk M, Walaszek Z, Slaga TJ and Hanausek M: Effects of desipramine on the cell cycle and apoptosis in Ca3/7 mouse skin squamous carcinoma cells. Int J Mol Med 25: 861-867, 2010.

22. Parker KA, Glaysher S, Hurren J, Knight LA, McCormick D, Suovouri A, Amberger-Murphy V, Pilkington GJ and Cree IA: The effect of tricyclic antidepressants on cutaneous melanoma cell lines and primary cell cultures. Anticancer Drugs 23: 65-69, 2012.

23. Jeon SH, Kim SH, Kim Y, Kim YS, Lim Y, Lee YH and Shin SY: The tricyclic antidepressant imipramine induces autophagic cell death in U-87MG glioma cells. Biochem Biophys Res Commun 413: 311-317, 2011.

24. Lu T, Chou CT, Liang WZ, Yu CC, Chang HT, Kuo CC, Chen WC, Kuo DH, Ho CM, Shieh P and Jan CR: Effect of antidepressant doxepin on $\mathrm{Ca}^{2+}$ homeostasis and viability in PC3 human prostate cancer cells. Chin J Physiol 58: 178-187, 2015.

25. Wang YY, Chen YK, Hsu YL, Chiu WC, Tsai CH, Hu SC, Hsieh PW and Yuan SF: Synthetic $\beta$-nitrostyrene derivative CYT-Rx20 as inhibitor of oral cancer cell proliferation and tumor growth through glutathione suppression and reactive oxygen species induction. Head Neck 39: 1055-1064, 2017.

26. Tsai CH, Hung AC, Chen YY, Chiu YW, Hsieh PW, Lee YC, Su YH, Chang PC, Hu SC and Yuan SF: 3'-hydroxy-4'-methox $y$ - $\beta$-methyl- $\beta$-nitrostyrene inhibits tumorigenesis in colorectal cancer cells through ROS-mediated DNA damage and mitochondrial dysfunction. Oncotarget 8: 18106-18117, 2017.

27. Messerschmitt PJ, Rettew AN, Schroeder NO, Brookover RE, Jakatdar AP, Getty PJ and Greenfield EM: Osteosarcoma phenotype is inhibited by 3,4-methylenedioxy- $\beta$-nitrostyrene. Sarcoma 2012: 479712, 2012

28. Calgarotto AK, da Silva Pereira GJ, Bechara A, ParedesGamero EJ, Barbosa CM, Hirata H, de Souza Queiroz ML, Smaili SS and Bincoletto C: Autophagy inhibited Ehrlich ascitic tumor cells apoptosis induced by the nitrostyrene derivative compounds: Relationship with cytosolic calcium mobilization. Eur J Pharmacol 678: 6-14, 2012.

29. Pettit RK, Pettit GR, Hamel E, Hogan F, Moser BR, Wolf S, Pon S, Chapuis JC and Schmidt JM: E-Combretastatin and $E$-resveratrol structural modifications: Antimicrobial and cancer cell growth inhibitory $\beta-E$-nitrostyrenes. Bioorg Med Chem 17: 6606-6612, 2009.

30. He Y, Varadarajan S, Muñoz-Planillo R, Burberry A, Nakamura Y and Núñez G: 3,4-Methylenedioxy- $\beta$-nitrostyrene inhibits NLRP3 inflammasome activation by blocking assembly of the inflammasome. J Biol Chem 289: 1142-1150, 2014.

31. Carter KC, Finnon YS, Daeid NN, Robson DC and Waddell R: The effect of nitrostyrene on cell proliferation and macrophage immune responses. Immunopharmacol Immunotoxicol 24: 187-197, 2002.

32. Jain N, Yada D, Shaik TB, Vasantha G, Reddy PS, Kalivendi SV and Sreedhar B: Synthesis and antitumor evaluation of nitrovinyl biphenyls: Anticancer agents based on allocolchicines. Chem Med Chem 6: 859-868, 2011.

33. Kim JH, Kim JH, Lee GE, Lee JE and Chung IK: Potent inhibition of human telomerase by nitrostyrene derivatives. Mol Pharmacol 63: 1117-1124, 2003.

34. Park J and Pei D: trans-Beta-nitrostyrene derivatives as slowbinding inhibitors of protein tyrosine phosphatases. Biochemistry 43: 15014-15021, 2004.

35. Villar JA, Lima FT, Veber CL, Oliveira AR, Calgarotto AK, Marangoni S and da Silva SL: Synthesis and evaluation of nitrostyrene derivative compounds, new snake venom phospholipase A2 inhibitors. Toxicon 51: 1467-1478, 2008. 
36. Byrne AJ, Bright SA, Fayne D, McKeown JP, McCabe T, Twamley B, Williams C and Meegan MJ: Synthesis, antiproliferative and pro-apoptotic effects of nitrostyrenes and related compounds in Burkitt's lymphoma. Med Chem 14: 181-199, 2018.

37. Lanemo Myhrinder A, Hellqvist E, Sidorova E, Söderberg A, Baxendale H, Dahle C, Willander K, Tobin G, Bäckman E, Söderberg O, et al: A new perspective: Molecular motifs on oxidized LDL, apoptotic cells, and bacteria are targets for chronic lymphocytic leukemia antibodies. Blood 111: 3838-3848, 2008.

38. Chou TC and Talalay P: Quantitative analysis of dose-effect relationships: The combined effects of multiple drugs or enzyme inhibitors. Adv Enzyme Regul 22: 27-55, 1984

39. McElligott AM, Maginn EN, Greene LM, McGuckin S, Hayat A, Browne PV, Butini S, Campiani G, Catherwood MA, Vandenberghe E, et al: The novel tubulin-targeting agent pyrrolo-1,5-benzoxazepine-15 induces apoptosis in poor prognostic subgroups of chronic lymphocytic leukemia. Cancer Res 69: 8366-8375, 2009.

40. Werner JM, Eger K and Jürgen Steinfelder H: Comparison of the rapid pro-apoptotic effect of trans-beta-nitrostyrenes with delayed apoptosis induced by the standard agent 5-fluorouracil in colon cancer cells. Apoptosis 12: 235-246, 2007.

41. Rahmani-Nezhad S, Safavi M, Pordeli M, Ardestani SK Khosravani L, Pourshojaei Y, Mahdavi M, Emami S, Foroumadi A and Shafiee A: Synthesis, in vitro cytotoxicity and apoptosis inducing study of 2-aryl-3-nitro- $2 \mathrm{H}$-chromene derivatives as potent anti-breast cancer agents. Eur J Med Chem 86: 562-569, 2014.
42. Burke RT, Meadows S, Loriaux MM, Currie KS, Mitchell SA, Maciejewski P, Clarke AS, Dipaolo JA, Druker BJ, Lannutti BJ and Spurgeon SE: A potential therapeutic strategy for chronic lymphocytic leukemia by combining Idelalisib and GS-9973, a novel spleen tyrosine kinase (Syk) inhibitor. Oncotarget 5: 908-915, 2014

43. Bodo J, Zhao X, Sharma A, Hill BT, Portell CA, Lannutti BJ, Almasan A and his ED: The phosphatidylinositol3-kinases (PI3K) inhibitor GS-1101 synergistically potentiates histone deacetylase inhibitor-induced proliferation inhibition and apoptosis through the inactivation of PI3K and extracellular signal-regulated kinase pathways. Br J Haematol 163: 72-80, 2013.

44. de Rooij MF, Kuil A, Kater AP, Kersten MJ, Pals ST and Spaargaren M: Ibrutinib and idelalisib synergistically target BCR-controlled adhesion in MCL and CLL: A rationale for combination therapy. Blood 125: 2306-2309, 2015.

45. Panayiotidis P, Jones D, Ganeshaguru K, Foroni L and Hoffbrand AV: Human bone marrow stromal cells prevent apoptosis and support the survival of chronic lymphocytic leukaemia cells in vitro. Br J Haematol 92 92: 97-103, 1996.

46. Lagneaux L, Delforge A, De Bruyn C, Bernier M and Bron D: Adhesion to bone marrow stroma inhibits apoptosis of chronic lymphocytic leukemia cells. Leuk Lymphoma 35: 445-453, 1999.

47. Bartels M, Calgarotto AK, Martens AC, Maso V, da Silva SL, Bierings MB, de Souza Queiroz ML and Coffer PJ: Differential effects of nitrostyrene derivatives on myelopoiesis involve regulation of C/EBP $\alpha$ and p38MAPK activity. PLoS One 9: e90586, 2014. 